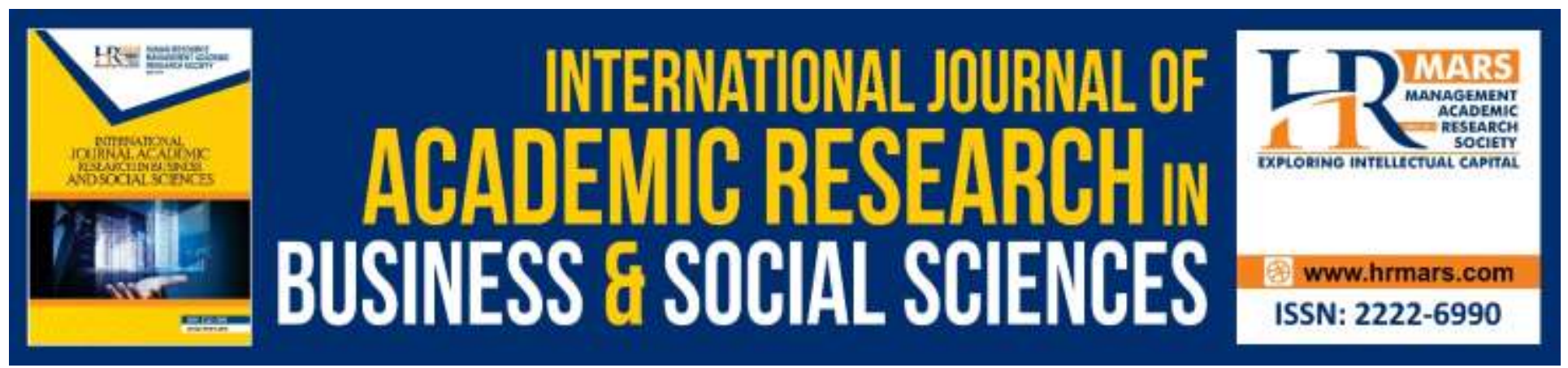

\title{
Effect of the Peace Education Program on the Children's Emotional Behavior in Oman
}

Mahfouda Rashid AI Mushaqiri, Zahari Bin Ishak \& Wail Muin Ismail

To Link this Article: http://dx.doi.org/10.6007/IJARBSS/v10-i5/7192

DOI:10.6007/IJARBSS/v10-i5/7192

Received: 15 March 2020, Revised: 22 April 2020, Accepted: 28 April 2020

Published Online: 10 May 2020

In-Text Citation: (Mushaqiri et al., 2020)

To Cite this Article: Mushaqiri, M. R. Al, Ishak, Z. Bin, \& Ismail, W. M. (2020). Effect of the Peace Education Program on the Children's Emotional Behaviour in Oman. International Journal of Academic Research in Business and Social Sciences, 10(5), 252-272.

Copyright: (C) 2020 The Author(s)

Published by Human Resource Management Academic Research Society (www.hrmars.com)

This article is published under the Creative Commons Attribution (CC BY 4.0) license. Anyone may reproduce, distribute, translate and create derivative works of this article (for both commercial and non-commercial purposes), subject to full attribution to the original publication and authors. The full terms of this license may be seen

at: http://creativecommons.org/licences/by/4.0/legalcode

Vol. 10, No. 5, 2020, Pg. 252 - 272

http://hrmars.com/index.php/pages/detail/IJARBSS

JOURNAL HOMEPAGE

Full Terms \& Conditions of access and use can be found at

http://hrmars.com/index.php/pages/detail/publication-ethics 


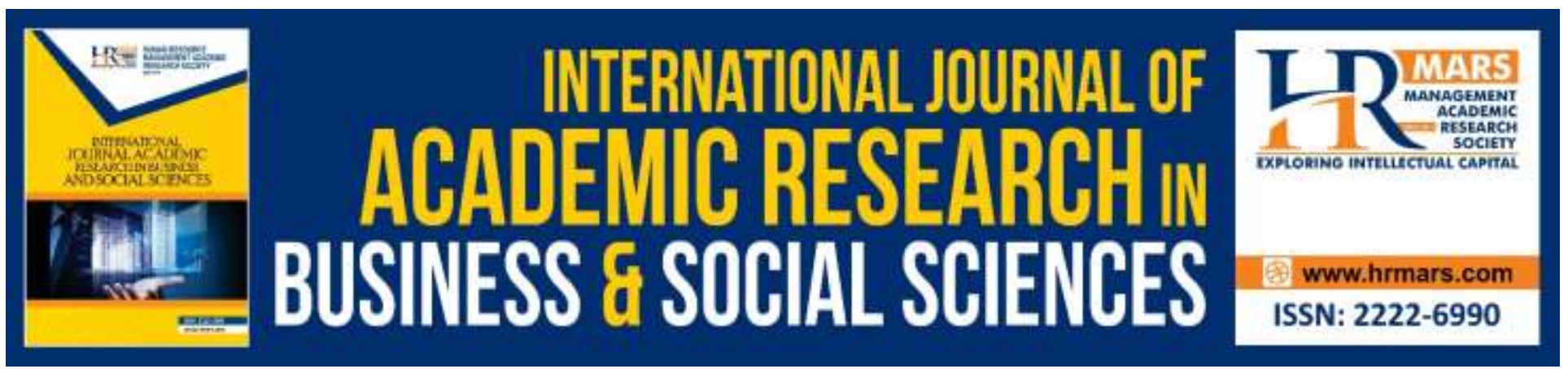

\title{
Effect of The Peace Education Program on The Children's Emotional Behaviour in Oman
}

\author{
Mahfouda Rashid Al Mushaqiri, Zahari Bin Ishak \& Wail Muin Ismail \\ University of Malaya, Faculty of Education \\ Email: mahfoodha1974@hotmail.com
}

\begin{abstract}
The present study aims at investigating the procedures and processes that facilitate peace education programs (PEP) for pre-school children in the Sultanate of Oman. The main issue that this study tries to handle is that Omani educational curriculum is entirely based on traditional approaches and methods that overwhelmingly lack to dynamism and modernism of well-formulated modern criteria of primary-school curriculum. This thus makes the curriculum not keep up with the technological advances concerning school education. The study adopts experimental research method and pictorial estimate. The study proposes systematically effective methods, procedures and processes of classroom teaching. This is presented in a well-formulated peace education program targeting preschool children aged between 4 to 6 years. The proposed program consists of 28 training sessions to be conducted in 15 weeks at the rate of one hour per session. The study finds that it is very essential to train and teach children importance of peace since childhood, as this helps them feel inner peace, satisfied with themselves and with the surrounding environment around them. Therefore, the possibility of children's being violent is very less.
\end{abstract}

Keywords: Peace Education, Emotion Behavior, Children.

\section{Introduction}

Peace is something intrinsic that all people need and look for. Spreading tranquility, happiness, harmony and balance in society is a factor beyond peace. It is peace of mind full of love that people need to live in tranquility. Psychological peace and self-alignment top the spiritual pyramid to live in comfort and happiness. Peace can be reached through a well-planned continuous training of how to mutually successfully deal with other people. (Al-Sharqawi, 2014). Peace is a human need, without which people live in terror and fear and lose their balance. This thus makes them consider and deal with the surroundings as enemies, lose other people's trust and respect. Peace education in UNICEF refers to the process of promoting knowledge, skills, attitudes and values needed to bring behavioral changes that support children, youth and adults and prevent conflict and violence. Furthermore, peace education helps children to peacefully resolve conflict; and create the conditions conducive to peace at personal, social and national levels (Nations, 2015). Peace education is considered worthy in both stable and unstable countries. As continuous behavioral changes occurring in children and 
adults over time, effective peace education is a necessarily long-term process often based in schools and other learning environment, where the entire community should ideally participate (Al-Saeed, 2010). The present study promotes the idea of implementing peace in children, although they live in a conflict-free environment. With the technology, the world has turned into a small village, so we can easily get breaking news and recent updates of what is going on. Children have become more violent than the adults, because of being affected with all that they have been going through. Such violence is reflected in their choice of game when interacting with one another to solve problems.

In order to encourage society to live in peace, internal peace must exist in individuals at early age. That is children should have a peaceful life since childhood. Internal peace is an internal psychological feeling that makes children accept themselves and others with their defects and advantages. This internal peace is the cornerstone for tolerance, cooperation, love, safety. When individuals enjoy internal peace, they have reached the peak of inner peace as their behavior is affected accordingly (Al-Sahrawi, 2014).

Given the importance of starting internal peace to ensure universal peace, pre-school education is the most important stage in a person's life. The experiences gained at this stage also greatly affect the lives of next generations and nations, which are largely measured by the extent of our interest at this stage (Al-Saidi, 2013). Emotional behavior is one of the most important skills to be given to a child. The basis of these skills is laid in pre-school education.

Many studies have focused on peace education i.e. a study conducted in the United States of America, analyzing 100 programs about peace education from kindergarten to high school. He found that there were no clear limits and no criteria for what should be included into peace education programs. The study was analytically conducted, concluding the key elements of peace education programs such as: cooperation, conflict resolution, non-violence, human rights, social harmony, learning resources. Besides that, components of knowledge, behavior and expertise are included.

Goals of peace education have been defined in this way as social steps through which peace can be achieved. This includes equal rights and equality in the power of everyone in society, as well as non-violence, conflict resolution and respect for human rights (Al-Saidi, 2013). Violent television programs and videos that children watch crystallize and promote violence as well as teach children to use disrespectful taboo words and expressions. (Al-Tamimi, 2012). Watching television more than four hours a day reduces the psychological, emotional and social development of children. So we have to pay attention to inculcate values in children and take care of them until they are ready to interact in society in a way that helps them communicate with those around them easily and positively, which brings peace and love to the world (Tillman \& Colomina, 2001).

\section{Statement of the Problem}

In eighties and nineties (in the beginning of the Renaissance in Oman), the Omani society put a remarkable organized interest concerning children's rights. The focus, however, was more directed on children's literacy and numeracy than on inculcating the values of peace in children. This in turn had a negative impact on the behavior of children due to the negative role of media in portraying children in cartoons, which implants many negative images in children's mind and cognition. Nowadays, it is different from the past because of many external influences affecting children. Moreover, today's family is much busy working outside home. This thus gives children an opportunity to spend much time watching TV. This study tries to solve the issues of Omani curriculum having been taught for a long time. The problem of this study, according to the evaluation conducted by UNICEF 
2010, lies in the fact that school children in Oman suffer from some issues related to spirituality, which in turn does not help children acquire good values. This is believed to be due to children's negative acquisition of some behaviors presented by games and cartoon movies. This has negatively affected children and made them rude, violent and introvert. The core issue that this study tries to handle and investigate is that Omani educational curriculum relies on based-traditional teaching approaches lacking dynamic mechanisms of modern curriculum able to keep pace with technological advances that significantly develop school system .

\section{Objectives of the Study}

This study aims at constructing a peace education program (PEP) that manifests the emotional behavior in children. The researcher investigates the efficacy of this program on preschool children in Oman. According to Oman Vision 20/40, Oman seeks to be among the top ten countries that enjoy world peace (Supreme Planning Council, 2019). The present study aims at supporting Oman's vision 20/40 for reaching the forefront of peace. The main purpose of this study is to spread the values of peace education in the behavior of children in the Sultanate of Oman. It also aims to determine the impact of the Peace Education Program on the emotional behavior of preschool children. The study mainly aims to:

1. Identify if there are significant differences in self-awareness of preschool children between the experimental and the control group of the (PEP).

2. Identify if there are significant differences in emotions management of preschool children between the experimental and the control group of the (PEP).

3. Identify if there are significant differences in empathy of preschool children between the experimental and the control group of the (PEP).

4. Identify if there are significant differences in motivation of preschool children between the experimental and the control group of the (PEP).

5. Assess if there are significant differences in the emotional behavior of preschool children between the experimental and the control group of the (PEP).

\section{Research Hypothesis}

This study examines the accuracy of the following null hypotheses:

1. There are significant differences in self-awareness of preschool children before and after introducing the PEP.

2. There are significant differences in emotions management of preschool children before and after introducing the PEP.

3. There are significant differences in empathy of preschool children before and after introducing the PEP.

4. There are significant differences in motivation of preschool children before and after introducing the PEP.

5. There are significant differences in the emotional behavior of preschool children between the experimental and the control group.

\section{Significance of the Study}

As far as the theoretical part is concerned, the importance of this study lies in its presentation of some important studies concerning training about peace education at pre-school stage. As far as the 
experimental part is concerned, the significance of this study lies in the fact that it enables preschool teachers to use the skills of peace education to enhance children's behavior. It also fills a research gap and enriches the research library where no other studies have tackled such an issue. This study is unique that it focuses on pre-school and basic education in the Ministry of Education in Oman. This is in order to implement peace education in the curriculum by conducting a daily training program for pre-school students, teachers and supervisors. Furthermore, it supports the update of supervisory methods, methods of measurement and evaluation. The findings of this study may help children control their feelings so that they can affect the feelings of others and have positive selfawareness about ...themselves and those around them. To the researcher's best knowledge, the current study is considered the first to investigate peace in educational sector in Oman. It is also the first to enrich the Omani curriculum for pre-school education, Which encourages more specialized training programs for teachers? The study may be also considered unique to enrich educational curriculum at university level in Oman. The activities, games and stories used by the researcher to conduct this study are found effective tools that should be used by children to increase their motivation towards learning. Furthermore, the results of the study can also help improve Omani curriculum and teachers to adopt skills and techniques through which they become messengers of peace.

\section{Empirical Definitions \\ Peace Education Program (PEP)}

The aim of this program is to spread the culture of non-violence and respect for human rights, respect and solidarity among peoples, intercultural dialog, linking peace to democratic participation and sustainable human development. It also encourages social participation, the free flow and sharing of information and knowledge, the contribution to conflict prevention and peace-building and the achievement of equality between men and women (Al-Saeed, 2010).

\section{Emotional Behavior (EB)}

It is about children's ability to pay attention of good perception of emotions, selffeeling, understanding, formulation and organization. EB also concerns with children's ability to observe the emotions of others and their feelings in order to interact and enjoy with them in positively emotional and social relationships, which thus helps them to learn more social skills (Othman \& Rizk, 2002).

\section{Literature Review}

Goleman (1998) came up with new explanation for the causes of psychological and behavioral problems that occur in families and communities. In his commentary on studies and research conducted on the human brain over the past two decades, he wrote about the emotional structure of the brain that explains how strong emotions dominate the human mind processes and how the decline in emotional intelligence causes many problems among humans, which negatively affects physical and psychological health. Goleman suggested a model of emotional intelligence based on individual characteristics, including the individual's own abilities and motivations (Sulaimani, 2015). Eco-Peace, a more recently developed branch of peace education, calls for the need to create peace in the world including all living things as well as our green nature (Brenes, 2008). Political systems create an education for sustainability as an element of peace 
education (Brenes, 2008). Approaches to peace education vary widely, but all hold similar characteristics and goals as they are all concerned with cultivating citizens of a cosmopolitan perspective in order to be able to establish a fair society (Shore, 1991).

Early childhood is a time when a child acquires developmental capabilities at different levels. The interplay of language, cognition, social-emotional capacities and physical abilities come intentionally into use more frequently. There are 387 cases of abuses against children in Oman. This happened between January and June 2018. There is a hotline in the Ministry of Social Development to report any cases of abuse (Al-Hajri, 2018). Despite the existence of the Omani Children's Code issued (Ministry of Social Development, 2014), this is not enough because children need to learn how to take preventive procedures before the incident in order to protect themselves from any abuse that may occur. Peace education in early childhood experiences can be extremely influential in building a child's future capacities for peace such as empathy, emotional regulation and behavioral control. This is why peace in early childhood is so important, as it helps uncover optimal developmental periods of the brain. The early years of life are considered "prime time" for brain development, which can affect a child's social capacities, which are critical to preconditions necessary for peace. Thus, early childhood should be much taken care of in order to build blocks for our future peace leaders (Reardon, 2009). Children can get rich experiences from nature. These experiences provide them with strong learning and developmental opportunities. Providing time in nature allows children at early childhood level to have unique opportunities for growth at all levels including social, emotional, cognitive, language, and physical. Outdoor time in nature grants children an opportunity to be involved in different social and physical activities including self-control, agility, body awareness, successful planning, coordination, as well as active communication. It also helps children acquire emotional-social skills and cognitive endeavors. Outdoors in nature help children to use problem-solving and decision-making skills in an ever changing and unpredictable environment. It allows them to develop play and communication skills crucial to language, social, and emotional development. It also enhances opportunities for children to find patterns, similarities and differences using critical thinking and creative skills while developing a bond with nature and being exposed to a bigger interconnected picture of the world. Furthermore, it provides opportunities for healthy developmental growth, opportunities for the integration of peace education and building the child's capacity for understanding peace (Alfonso, 2014).

Emotions, considered a means to communicate, reflect children's beliefs, goals and express their wishes and intentions. Emotional behavior is the ability of individuals to control their emotions in order to distinguish between them and employ this ability to guide the individual's thinking and self-act. Goleman has defined emotional behavior as a range of emotional and social skills enjoyed by the individual (Othman \& Rizk, 2002).

Goleman (2000) explains five basic dimensions of constituting emotional behavior:

1- Emotional knowledge (self-awareness): according to Socrates's wisdom "know yourself", means the individual's awareness of their own feelings. Goleman referred to the consciousness and called it self-awareness. This self-reflective awareness makes the mind observe and study the experience itself and its emotions (Goleman, 2000).

2- Emotional management: emotional management comes from balancing rather than emotional suppression, since all feelings have value and importance. Aristotle noted that what we are looking for and seeking is the appropriate emotion that fits the situation because increasing extremism in emotions leads to loss of personal balance (Al-Abdali, 2010). 
3- Emotional regulation (self-motivation): emotions affect our ability to use our mental potential to the extent that it can be hampered or prevent the development of our abilities to think and plan. This thus affects how we perform our duties in our daily life (Al-Abdali, 2010).

4- Empathy (comprehension): ability to recognize and understand others' feelings and respond to them. The more individuals are able to accept a feeling, and the opportunity to appear, the more they are able to read and interact with others' feelings (Goleman, 2000).

5- Social Networking: the ability to manage emotions with others is the basis to make relationships in a healthy manner. Management of interpersonal relations will require two emotional skills: Selfcontrol and emotion. When we need to manage relationships with others, we have to have some self-control (Goleman, 2000).

Emotions are fundamental to the stability, rationality and reasonability of human behavior. Love, sacrifice, and parental care for the welfare of children are examples of controlling emotions in human behavior and its impact in one's life. Most studies have shown that few students with high emotional intelligence, even though being smokers or alcohol abusers, are less aggressive with their classmates, and more socially accepted by their teachers, than those students with low emotional intelligence accept. This proves the role of emotional intelligence in reducing behavioral problems and violence among students (Dhaifullah, 2008).

This study deals with four main dimensions mentioned above: 1- self-awareness (SA), 2- emotions management (EM), 3-empathy (E) and 4- motivation (M)

\section{Preschool Educational System in Oman}

The Ministry of Education attaches great importance to pre-school education, which includes kindergartens, classrooms and schools of learning the Qur'an. The ministry is still working to raise the enrollment rate by encouraging private sector contribution in providing this service. According to the vision of Ministry of education in Oman, the aim of education is to prepare good citizens capable of assuming responsibilities and able to understand the natural, social and cultural environment and develop their basic skills to be able to transfer ideas and follow the scientific method of research and thinking and guide the individual towards healthy growth and raise the level of health, socially and economically (Education, 2017). Furthermore, The Ministry of Education in Oman has adopted a selflearning approach that makes students the center of education process. It prepares them to continue learning and to deal with the scientific and research thinking method, to investigate facts and knowledge and to deal with them interactively and critically (Education, 2011).

Developing the personality, skills, and direction of the Omani child physically and mentally is the main aim of the Omani curriculum (Wave, 2013). The curriculum also aims at providing children with saving habits, and rational consumption and developing child's creativity and innovation (Diaa Almustakball, 2013).

\section{Previous Related Studies}

1- Johnson (2001) suggested five steps to train students to contribute to the dissemination of a culture of peace inside and outside the school in America.The aim of these steps are to help 1students know their own perspective, 2-know the solution through negotiation, 3- mediate conflicts among colleagues, and 4- receive continuous training. Johnson focused on kindergarten and elementary students from different rural, suburb and city schools. The data was collected through observations and interviews, forms of conflict report, and oral responses to conflict scenarios, and 
INTERNATIONAL JOURNAL OF ACADEMIC RESEARCH IN BUSINESS AND SOCIAL SCIENCES Vol. 10, No. 5, May, 2020, E-ISSN: 2222-6990 @ 2020 HRMARS

actual conflicts occurring between classmates. The results showed that students need to learn throughout the year the necessary procedures to settle disputes, apply conflict resolution procedures in actual conflicts.

2- Zidane and Imam (2002) conducted a study about the relationship between emotional intelligence with its five dimensions and each of the different learning methods, and some dimensions of character and personality. The study was conducted on a sample of (355) students, ddivided into (180) male students and (175) female students of different scientific disciplines. The results showed that there is a weak and non-statistically significant correlation between introversion, most dimensions of emotional intelligence (Empathy, emotional management, regulation of emotions and self-awareness) and the existence of a statistically significant positive correlation in the dimension of communication and in the total degree of emotional intelligence. The study also stressed that neuroticism has a negative relationship, which is statistically significant in all dimensions of emotional intelligence except with some sympathy and self-awareness where there is a definite positive relationship between them.

3- McKinley (2007) investigated the forms of conflict occurring in early childhood and their relation with peacemaking. The researcher collected data through field observations. The study sample consisted of 39 children aged between 4 to 5 years in rural areas. The study identified 5 types of conflict in early childhood:1- entry into play, 2-respect for rules, 3-possession of objects, 4- take the role of another child and 5- natural harm. The study found that post-conflict peace is very rare in early childhood.

4- Sommerfelt \& Vambheim's (2008) study investigated the impact of peace education and confronting violence. They used unconventional methods that rely on the power of mind and body to reduce violence and maintain internal and external peace. The study was applied randomly on a sample of 120 students aged between 6 to14 years old. Students were trained to practice some yoga exercises and similar relaxation exercises to strengthen their ability to control reactions that lead to violence such as yelling, anger etc. The results showed that there was improvement in the participants' behavior as there is a lesser degree in their violent responses to daily situations such as delayed transportation, getting up late, or interacting with colleagues.

5- Rayasti's study (2010), on the other hand, aimed to examine the relationship between emotional intelligence and its relation to psychological and social compatibility. The study was applied on a sample of children ranging between 13 to 16 years old. A set of measures and tools were used in this study i.e. the Social and Cultural Level Questionnaire formulated by Hamid was adopted in order to measure psychological and social compatibility. Furthermore, the researcher adopted Intelligence Measure formulated by Saleh. The study sample included 400 students from the preparatory and secondary levels. The sample of the selected study was divided into (192) males and (208) females. The results of the study showed that there is a relationship between the emotional intelligence of each dimension and between understanding of conscience and consciousness. The second dimension includes empathy with others, the third includes management of conscience, and the fourth dimension is social skills, and all dimensions of psychological and social compatibility at the level of significance 0.001 . This indicates the emotional intelligence being linked to the psychological and social compatibility dimensions. This also indicates that there is a high level of emotional intelligence allowing the ability to social and psychological compatibility with social conditions, family or school. 
6- Al Hashemi (2016) investigated the effectiveness of a proposed program in educational games for developing some social skills in Preparatory Educational Children. The study sample included 52 children between 5-6 years old, divided equally into two groups (experimental and control). The study adopted an experimental research method. The statistical data were treated by SPSS. The hypotheses were examined by calculating the $t$-test, the analysis of covariance and square ETA ( $\eta 2)$. The study concluded that children's social skills improved after the program was completed.

\section{Methodology}

The present study is based on the quasi-experimental approach to evaluate the effect of the Peace Education Program (as an independent variable) concerning emotional behaviour (as a dependent variable) of pre-school children in Oman. The researcher used a quasi - experimental design approach for both control group and experimental group. Children from KG2 class were selected from two different classes to set for a pre-test. Then, the experimental group was subject to the independent variable, while the control group was not. Finally, at the end of the experiment, the experimental and control groups were given the post-test to evaluate the effect of the independent variable application.

\section{Procedures Used in Studying the Effect of Peace Education Program (PEP) on the Emotional Behaviour of Pre-School Children in Oman}

1 - Building a peace education program (PEP).

2- Preparing estimation in peace education to measure the emotional behavior (EB) of children. This contains three dimensions identified by 19 items (19-37): 1- self-awareness (SA), consisting of 5 items, 2-emotions Management (EM) consisting of 4 items and 3-empathy (E) consisting of 6 items. Motivation (M) consists of 4 items. This part of the estimate consists of 19 images distributed to the four dimensions of emotional behaviour. Each position consists of a picture followed by two pictures of choice. In a number of situations, there are only two pictures for the child to choose in accordance with their behaviour in specific situations. The participants who select the correct answer will be given 2 points. Those who select wrong answer will be given 1 point.

Since the population is scattered in a wide geographic area of 11 districts in Oman, the researcher used the technique of stratified class sampled by geographical location. In this study, the researcher chose the sample in a deliberate manner, by taking the opinion of supervisors in the Ministry of Education about the schools that meet the following criteria: 1- schools with children showing behavioral problems, whether emotional or social, 2- enough participants to involve in the study, and 3- school should cooperate and facilitate all the necessary procedures for the researchers to carry on the experiment. After this the researcher visited the school and obtained approval of the school administration to implement the program of study for the children of KG2 in the Little Explorer Kindergarten in the south Al Ma'abila during the second semester of the academic year 2018/2019. The researcher then divided the children into two experimental and control groups after getting teachers and parents' approval. In addition, the sample of the study $(N=80)$ was homogeneous in gender and number of children between the experimental and control groups. The study included 42 males and 38 females with 40 children in the experimental group and 40 in the control group. 
INTERNATIONAL JOURNAL OF ACADEMIC RESEARCH IN BUSINESS AND SOCIAL SCIENCES Vol. 10, No. 5, May, 2020, E-ISSN: 2222-6990 ㄷ 2020 HRMARS

\section{Data Analysis and Findings}

Under this section, data is analyzed, the main study hypotheses are answered and then conclusions are accordingly drawn.

\section{Validity of Hypotheses according to Standardized Tests}

To ensure sample normality, normality tests were conducted, ANCOVA test was conducted as an inferential analysis, in order to examine the study hypothesis.

Table (1): Normality tests for study variables

\begin{tabular}{|c|c|c|c|c|c|}
\hline & Variable & Mean & SD & Skewness & Kurtosis \\
\hline \multirow{4}{*}{ 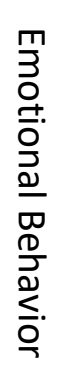 } & Self-Awareness & 1.7650 & .20256 & -.524 & -.339 \\
\hline & $\begin{array}{l}\text { Emotions } \\
\text { Management }\end{array}$ & 1.7578 & .23861 & -.546 & -.622 \\
\hline & Empathy & 1.7458 & .18966 & -.340 & -.688 \\
\hline & Motivation & 1.7234 & .23053 & -.371 & -.561 \\
\hline
\end{tabular}

Table (1) shows the values of skewness, kurtosis as the normality tests, the mean and the standard deviation for each variable of the main study variables. The results show that all variables are considered normally distributed as the skewness and kurtosis values are between \pm 2 , which is considered acceptable according to George \& Mallery (2016).

Figures 1,2,3,4 show the normality curves, which indicate clearly the bell shape.
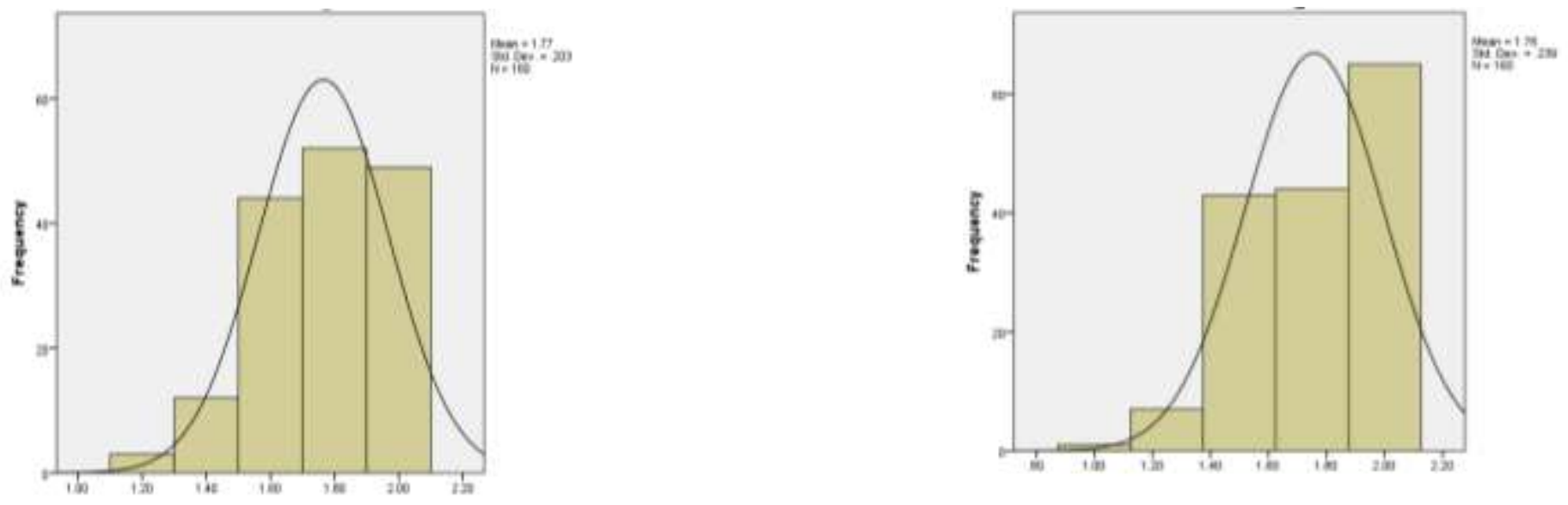

Figure 2: Emotions Management 
INTERNATIONAL JOURNAL OF ACADEMIC RESEARCH IN BUSINESS AND SOCIAL SCIENCES Vol. 10, No. 5, May, 2020, E-ISSN: 2222-6990 ㄷ 2020 HRMARS

Figure 1: Self-Awareness

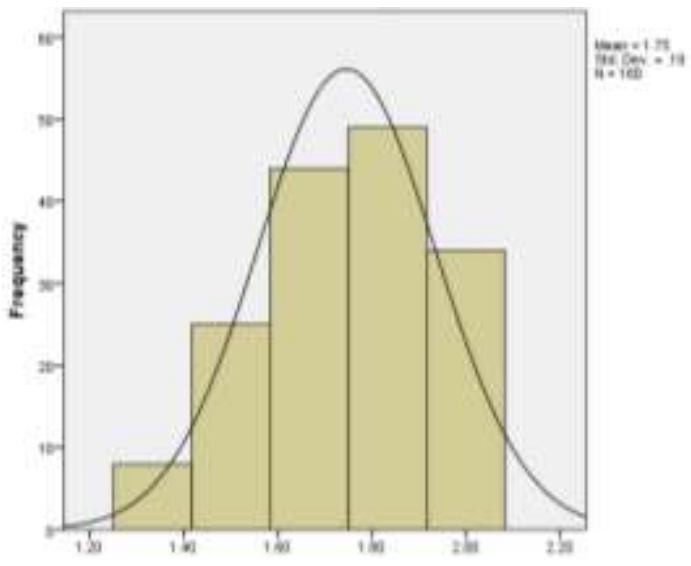

Figure 3: Empathy

Figure 4: Motivation

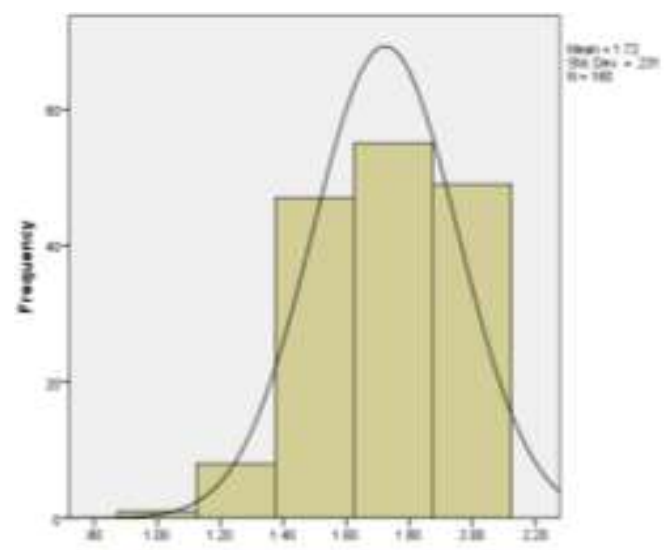

\section{Discussion of}

Research Questions by Testing Research Hypothesis

Testing Research Hypotheses

Table (2): ANOVA results for self-awareness

ANOVA Self-Awareness

\begin{tabular}{cccccc}
\hline & Sum of Squares & Df & Mean Square & F & Sig. \\
\hline Between Groups & .000 & 1 & .000 & .000 & 1.000 \\
\hline Within Groups & 3.118 & 78 & .040 & & \\
\hline Total & 3.118 & 79 & & \\
\hline
\end{tabular}

Sig. $<.05$

As shown in table (2), the significance level for ANOVA test is more than 0.05. This means there are no statistical differences between the independent variable (control and experimental groups) and the covariate variable (pre-test of self-awareness) of the self-awareness indicating that the ANCOVA assumption is verified.

\section{Testing Hypothesis 1 (ANCOVA Test)}

To test the first hypothesis, ANCOVA test is used whereas the independent variable is students' group (control and experimental), the dependent variable is the post-test and the covariate variable is the pre-test. The ANCOVA test results are shown in table (3). 
INTERNATIONAL JOURNAL OF ACADEMIC RESEARCH IN BUSINESS AND SOCIAL SCIENCES

Vol. 10, No. 5, May, 2020, E-ISSN: 2222-6990 @ 2020 HRMARS

Table (3): ANCOVA results for the first hypothesis

\begin{tabular}{ccccccc}
\hline \multirow{2}{*}{ Variable } & Test & Mean & S.D & F & Sig. & $\begin{array}{c}\text { Effect } \\
\text { Size \% }\end{array}$ \\
\hline \multirow{2}{*}{ Self-Awareness } & Control & $\mathbf{1 . 7 2 5 0}$ & .19579 & & & \\
\cline { 2 - 4 } & & & & & & \\
Experimental & $\mathbf{1 . 9 2 5 0}$ & .11712 & & .000 & $\mathbf{. 5 3}$
\end{tabular}

Sig. $<.05$

Table (3) shows that there are significant differences in self-awareness of preschool children between the experimental and the control group after receiving the peace education program (PEP) whereas the significance level $(\mathrm{F}=33.305$, Sig $=.000)$ which is less than .05 meaning that selfawareness of the preschool children significantly enhanced after receiving the PEP. This is indicated also by noticing the mean values before $(M=1.73)$ and after $(M=1.93)$. Moreover, the effect size in Self-Awareness in PEP between Experimental and Control showed that the influence medium with value more than 0.5 by Cohen's d.

As a result, we can accept the first hypothesis as the self-awareness of the preschool children has enhanced significantly after receiving the peace education program (PEP).

\section{Testing Hypothesis 2}

Table (4): ANOVA results for emotions management

ANOVA - Emotions Management

\begin{tabular}{cccccc}
\hline & Sum of Squares & Df & Mean Square & $F$ & Sig. \\
\hline Between Groups & .003 & 1 & .003 & .056 & .814 \\
\hline Within Groups & 4.369 & 78 & .056 & & \\
\hline Total & 4.372 & 79 & &
\end{tabular}

Sig. $<.05$

As shown in table (4), the significance level for ANOVA test is more than 0.05 . This means that there are no statistical differences between the independent variable (control and experimental groups) and the covariate variable (pre-test of emotions management) of the emotions management. This shows that the ANCOVA assumption is verified.

\section{ANCOVA Test (Second Hypothesis)}

To test the second hypothesis, ANCOVA test is used. The independent variable is students' group (control and experimental), the dependent variable is the post-test and the covariate variable is the pre-test. The ANCOVA test results are shown in table (5). 
INTERNATIONAL JOURNAL OF ACADEMIC RESEARCH IN BUSINESS AND SOCIAL SCIENCES

Vol. 10, No. 5, May, 2020, E-ISSN: 2222-6990 @ 2020 HRMARS

Table (5): ANCOVA results for the second hypothesis

\begin{tabular}{lcccccc}
\hline \multicolumn{1}{c}{ Variable } & Test & Mean & S.D & F & Sig. & $\begin{array}{r}\text { Effect } \\
\text { Size \% }\end{array}$ \\
\hline $\begin{array}{l}\text { Emotions } \\
\text { Management }\end{array}$ & Control & $\mathbf{1 . 6 6 8 8}$ & .22208 & & & \\
\cline { 2 - 4 } & Experimental & $\mathbf{1 . 9 7 5 0}$ & .07596 & & .000 & $\mathbf{. 6 8}$ \\
\hline
\end{tabular}

Sig. $<.05$

Table (5) shows that there are significant differences in emotions management of preschool children between the experimental and the control group after receiving the peace education program (PEP). The significance level is ( $\mathrm{F}=99.705$, Sig= .000) which is less than .05 . This means that emotions management of the preschool children significantly enhanced after receiving the PEP. This is clearly demonstrated in the main values before $(M=1.67)$ and after $(M=1.98)$. Furthermore, the effect size in Emotions Management in PEP between Experimental and Control showed medium impact with value more than 0.5 .

As a result, we can accept the second hypothesis that the emotions management of the preschool children have enhanced significantly after receiving the peace education program (PEP).

Table (6): ANOVA Results for Empathy

ANOVA - Empathy

\begin{tabular}{cccccc}
\hline & Sum of Squares & Df & Mean Square & $F$ & Sig. \\
\hline Between Groups & .006 & 1 & .006 & .201 & .656 \\
\hline Within Groups & 2.161 & 78 & .028 & & \\
\hline Total & 2.167 & 79 & & & \\
\hline
\end{tabular}

Sig. $<.05$

As shown in table (6), the significance level for ANOVA test is more than 0.05 . This means that there are no statistical differences between the independent variable (control and experimental groups) and the covariate variable (pre-test of empathy) of the empathy. This shows that the ANCOVA assumption is verified.

\section{Testing Hypothesis 3 (ANCOVA Test)}

To test the sixth hypothesis, ANCOVA test is used. The independent variable is students' group (control and experimental), the dependent variable is the post-test and the covariate variable is the pre-test. The ANCOVA test results are shown in table (7). 
INTERNATIONAL JOURNAL OF ACADEMIC RESEARCH IN BUSINESS AND SOCIAL SCIENCES

Vol. 10, No. 5, May, 2020, E-ISSN: 2222-6990 @ 2020 HRMARS

Table (7): ANCOVA results for the third hypothesis

\begin{tabular}{ccccccc}
\hline \multirow{2}{*}{ Variable } & Test & Mean & S.D & F & Sig. & $\begin{array}{r}\text { Effect } \\
\text { Size \% }\end{array}$ \\
\hline \multirow{2}{*}{ Empathy } & Control & $\mathbf{1 . 6 8 7 5}$ & .14709 & & & \\
\cline { 2 - 5 } & Experimental & 1.9625 & .07048 & & .000 & .77 \\
\cline { 2 - 4 } & & & & & &
\end{tabular}

Sig. $<.05$

Table (7) shows that there are significant differences in empathy of preschool children between the experimental and the control group after receiving the peace education program (PEP). The significance level $(F=145.890$, Sig $=.000)$ which is less than .05 means that empathy of the preschool children significantly enhanced after receiving the PEP. This is clearly demonstrated by the mean values before $(M=1.69)$ and after $(M=1.96)$. However, the effect size in Empathy in PEP between Experimental and Control showed medium impact with value more than 0.5 .

As a result, we can accept the third hypothesis that the empathy management of the preschool children have enhanced significantly after receiving the peace education program (PEP).

Table (8): ANOVA results for motivation

ANOVA - Motivation

\begin{tabular}{cccccc}
\hline & Sum of Squares & Df & Mean Square & $F$ & Sig. \\
\hline Between Groups & .000 & 1 & .000 & .000 & 1.000 \\
\hline Within Groups & 3.797 & 78 & .049 & & \\
\hline Total & 3.797 & 79 & & &
\end{tabular}

Sig. $<.05$

As shown in table (8), the significance level for ANOVA test is more than 0.05 . This means that there are no statistical differences between the independent variable (control and experimental groups) and the covariate variable (pre-test of motivation) of the motivation. This indicates that the ANCOVA assumption is verified.

\section{Testing Hypothesis 4 (ANCOVA Test)}

To test the fourth hypothesis, ANCOVA test is used. The independent variable is students' group (control and experimental), the dependent variable is the post-test and the covariate variable is the pre-test. The ANCOVA test results are shown in table (9). 
INTERNATIONAL JOURNAL OF ACADEMIC RESEARCH IN BUSINESS AND SOCIAL SCIENCES

Vol. 10, No. 5, May, 2020, E-ISSN: 2222-6990 @ 2020 HRMARS

Table (9): ANCOVA results for the seventh hypothesis

\begin{tabular}{|c|c|c|c|c|c|c|}
\hline Variable & Test & Mean & S.D & $\mathbf{F}$ & Sig. & $\begin{array}{l}\text { Effect } \\
\text { Size } \%\end{array}$ \\
\hline \multirow{2}{*}{ Motivation } & Control & 1.6438 & .20324 & \multirow{2}{*}{87.662} & \multirow{2}{*}{.000} & \multirow{2}{*}{.77} \\
\hline & Experimental & 1.9375 & .12339 & & & \\
\hline
\end{tabular}

Sig. $<.05$

Table (9) shows that there are significant differences in motivation of preschool children between the experimental and the control group after receiving the peace education program (PEP). The significance level $(F=87.662$, Sig $=.000)$ which is less than .05 means that motivation of the preschool children significantly enhanced after receiving the PEP. This is noticed in the main values before $(M=1.64)$ and after $(M=1.94)$. Nonetheless, the effect size in Motivation in PEP between Experimental and Control with value more than 0.5 indicating medium influences.

As a result, we can accept the fourth hypothesis that the motivation of the preschool children have enhanced significantly after receiving the peace education program (PEP).

Table (10): ANOVA results for emotional behaviors

ANOVA-Emotional Behaviors

\begin{tabular}{cccccc} 
& Sum of Squares & Df & Mean Square & $F$ & Sig. \\
\hline Between Groups & .000 & 1 & .000 & .002 & .967 \\
\hline Within Groups & .987 & 78 & .013 & & \\
\hline Total & .987 & 79 & & & \\
\hline
\end{tabular}

Sig. $<.05$

As shown in table (10), the significance level for ANOVA test is more than 0.05. This means there is not statistical differences between the independent variable (control and experimental groups) and the covariate variable (pre-test of emotional behaviors) of the emotional behaviors, which indicates that the ANCOVA assumption is verified. 
INTERNATIONAL JOURNAL OF ACADEMIC RESEARCH IN BUSINESS AND SOCIAL SCIENCES

Vol. 10, No. 5, May, 2020, E-ISSN: 2222-6990 @ 2020 HRMARS

\section{Testing Hypothesis 5 (ANCOVA Test)}

To test the fifth hypothesis, ANCOVA test is used. The independent variable is students' group (control and experimental), the dependent variable is the post-test and the covariate variable is the pre-test. The ANCOVA test results are shown in table (11).

Table (11): ANCOVA results for the ninth hypothesis

\begin{tabular}{lcccccc}
\hline Variable & Test & Mean & S.D & F & Sig. & $\begin{array}{c}\text { Effect } \\
\text { Size \% }\end{array}$ \\
\hline $\begin{array}{l}\text { Emotional } \\
\text { Behaviours }\end{array}$ & Control & $\mathbf{1 . 6 8 1 3}$ & .10669 & & & \\
\cline { 2 - 4 } & Experimental & $\mathbf{1 . 9 5 0 0}$ & .04419 & & $\mathbf{0 0 0}$ & $\mathbf{8 5}$ \\
\hline
\end{tabular}

Sig. $<.05$

Table (11) shows that there are significant differences in emotional behaviors of preschool children between the experimental and the control group after receiving the peace education program (PEP). The significance level $(F=298.524$, Sig $=.000)$ which is less than .05 means that emotional behaviors of the preschool children was significantly enhanced after receiving the PEP. This is noticed by the mean values before $(M=1.68)$ and after $(M=1.95)$. However, the effect size in Emotional Behaviors in PEP between Experimental and Control showed large impact with value more than 0.8 .

As a result, we can accept the fifth hypothesis that the emotional behaviors of the preschool children have enhanced significantly after receiving the peace education program (PEP).

\section{Summary of the Hypotheses}

According to the results of the statistical analysis, the study hypotheses can be summarized in table (12) as follows: 
INTERNATIONAL JOURNAL OF ACADEMIC RESEARCH IN BUSINESS AND SOCIAL SCIENCES Vol. 10, No. 5, May, 2020, E-ISSN: 2222-6990 @ 2020 HRMARS

Table (12): Hypotheses results summary

\begin{tabular}{|c|c|c|c|c|}
\hline No & Hypothesis & Sig & Effect Size & Result \\
\hline 1 & $\begin{array}{l}\text { There are significant differences in self- } \\
\text { awareness of preschool children between } \\
\text { the experimental an } \cdots . . . . . . . . \\
\text { group of the (PEP) }\end{array}$ & .000 & .53 & Accepted \\
\hline 2 & $\begin{array}{c}\text { There are significant differences in emotions } \\
\text { management of preschool children between } \\
\text { the experimental and the control group of } \\
\text { the (PEP) }\end{array}$ & .000 & .68 & Accepted \\
\hline 3 & $\begin{array}{l}\text { There are significant differences in empathy } \\
\text { of preschool children between the } \\
\text { experimental and the control group of the } \\
\text { (PEP) }\end{array}$ & .000 & .77 & Accepted \\
\hline 4 & $\begin{array}{c}\text { There are significant differences in } \\
\text { motivation of preschool children between } \\
\text { the experimental and the control group of } \\
\text { the (PEP) }\end{array}$ & .000 & .77 & Accepted \\
\hline 5 & $\begin{array}{c}\text { There are significant differences in the } \\
\text { emotional behaviors of preschool children } \\
\text { between the experimental and the control } \\
\text { group of the (PEP) }\end{array}$ & .000 & .85 & Accepted \\
\hline
\end{tabular}

\section{Discussions and Conclusions}

Under this section, the main study questions are answered and conclusions are drawn as follows:

Answer of Question 1 "are there any significant differences in self-awareness of preschool children before and after introducing the PEP?" There are significant differences in self-awareness of preschool children before and after introducing the PEP. The findings show that the behavior of preschool children in the experimental group improved significantly after being exposed to a peace education program. This shows the importance of the current study program in developing children's self-awareness. Furthermore, the results of the hypothesis are consistent with studies by (Al Rayasti, 2010., \& Al-Saidi, 2013). Consistency is concerned with the importance of training children to develop their emotional behavior. Our study however differs in that it shows and stresses the development of self-awareness in emphasizing the importance of applying the peace education program to children in Oman and its positive impact on students' lives.

Answer of Question 2 "are there any significant differences in emotions management of preschool children before and after introducing the PEP?" There are significant differences in emotions 
management of preschool children before and after introducing the PEP. The study finds that the behavior of children in the experimental group in emotions management has improved significantly comparing to their behavior before joining the PEP. This demonstrates the importance of the PEP in training all pre-school children in Oman. This includes the significance of emotional management in improving children's behavior in dealing with anger, understanding emotions and dealing with emotions of all kinds. This is consistent with studies of (Al-Saidi, 2013; Al Maimouni, 2018) concerning the presence of statistical significant differences in favor of the experimental group.

Answer of Question 3"are there any significant differences in empathy of preschool children before and after introducing the PEP?" There are significant differences in empathy of preschool children before and after introducing the PEP. The results of the current study show the development of the empathy of pre-school children who joined the PEP in the experimental group compared to their emotional behavior before the program. Furthermore, the results of the current study are consistent with studies of (Al Rayasti, 2010; Al-Saidi, 2013; Al Maimouni, 2018) concerning the importance of emotional behavior training and empathy.

Answer of Question 4 "are there any significant differences in motivation of preschool children before and after introducing the PEP?" There are significant differences in preschool children's motivation before and after introducing the PEP.

There are statistically significant differences in the motivation behavior of the children of the experimental sample after being introduced to the PEP. There is significant improvement in children's motivational behavior compared to their pre-program behavior. This is consistent with studies of (Johnson \& Johnson, 2001; Al Rayasti, 2010; \& Al Maimouni, 2018). This study shows statistical differences between those who are (not) trained in emotional behavior and motivation.

Answer of Question 5 "are there any significant differences in the emotional behavior of preschool children between the experimental and the control group?" There are significant differences in the emotional behavior of preschool children between the experimental and the control group. The results of this hypothesis show that there are statistically significant differences between the experimental group and the control group in the emotional behavior attributed to the experimental group that was exposed to the PEP. This is due to the importance of training all pre-school children in Oman in the peace education program and its inclusion in the curricula offered to children of this category, as well as training pre-school teachers in its application to make it easier for them to deliver correctly.

The significant difference between the experimental and control group concerning emotional behavior are based on the results of the post-estimation and this is in favor of the experimental group. Control group did not recognize the mistakes they made while answering tribal appreciation. This was due to not practicing the peace education program. This group thus did show any development or improvement in social and emotional behavior. This was consistent with studies of (Zidane \& Iman, 2002; Abu Al Latif, 2007; Al Rayasti, 2010; Al-Saidi, 2013; Al Hashemi, 2016; \& Al Maimouni, 2018). 


\section{Conclusions}

This study concludes that there is a positive impact of the peace education program on the emotional behavior of preschool children. The study shows that peace is an important prerequisite for the development of people's balanced life, especially in childhood stage. The study provides many techniques and measures that improve children's behavior through the PEP, which may thus support the curriculum in Oman. The study concludes that the PEP is likely to be beneficial to learners, teachers, curriculum designers, and educational policy-makers in Oman. The results of this study may, if to be implemented, improve the behavior of pre-school children and develop curricula and training methods. Having analyzed the most prevalent negative phenomena among pre-school children, their impact on the social and emotional behavior of children, and values they consider necessary for achieving peace in child's life, most of the teachers emphasized that children at this stage deal with the school's tools violently, cause damage most of the time, and not like participating with others. They use physical and verbal abuse as well as disrespecting the eldest and their classmates.

\section{Recommendations for Future Work}

It is necessary to conduct future studies expanding this work, as this study only targeted a population of one district in Oman. Hence, a future research may be needed to investigate all other parts of Oman and other countries in order to produce a general model. Future studies should cover a culturally diverse population with the ability to add new insights to studies concerning peace education. A future study about the impact of a peace education program concerning mental, spiritual or other aspects is suggested to be conducted on students at different stages of study and from different population areas. The researcher finally recommends a program be conducted for preschool children in order to help children learn some peace skills such as love, tolerance, honesty, cooperation, respect, happiness, dialogue and protection. This thus will enable children to grow in a peace-loving and peace-making environment.

\section{Motivation of this Study}

The main motivation that led the researcher to conduct this study was the fact that Omani educational system is still rather traditional and thus its teaching outcomes are neither satisfactory nor fruitful. Hence, the researcher decided to take action, conducting a new study that would contribute to the advances of this educational system. Thus, the strategies and techniques mentioned in this study, if considered by Ministry of Education, would rather improve the educational process in general in respect of peace, co-existence and tranquility.

\section{Acknowledgment}

This research received no specific grant from any funding agency in the public.

\section{References}

Abd Al Latif, F., AlGarwany, H., Almshrafi, A., Albactoshi, H., Mostafa, M., \& Sharkawi, R. (2007). The project of the skills of peace for the kindergarten child. Faculty of Kindergarten, Alexandria University, Egypt.

Al Hashemi, L. (2016). The effectiveness of a proposed program in the educational games for the development of some social skills in the children of preparatory education in the city of 
INTERNATIONAL JOURNAL OF ACADEMIC RESEARCH IN BUSINESS AND SOCIAL SCIENCES

Vol. 10, No. 5, May, 2020, E-ISSN: 2222-6990 @ 2020 HRMARS

Ouargla. University of Qasidi Marbah Ouargla, Algazair. Journal of Human and Social Sciences, 2016, No.11.

Al Rayasti, R. (2010). Emotional intelligence and its relation to psychological and social compatibility in a sample of children (13-16) years. Childhood studies, 6(13), 123- 154.

Al Maimouni, S. (2018). The effectiveness of a program of dynamic activities in the development of emotional stability of the kindergarten child of Kuwait. Benha University, Egypt.

Al-Abdali, S. (2010). Emotional intelligence and its relationship to both self-efficacy and marital compatibility for a sample of married teachers in the city of Macca. Saudi Arabia

Alfonso, S. (2014). Peace Education in Early Childhood Education. University of Toledo. Article Published in Volume 8(2): 167-188.

Al-Hajri, S. (2018). Sharp rise in child abuse cases in Jan-June 2018. Muscat Daily. On October 03, 2018. Oman.

Al-Saeed, N. (2010). An analytical study of the components of the culture of peace in children's stories published by the State Information Service and presented to the Egyptian child. (PhD), Ain Shams University, Egypt.

Al-Saidi, R. (2013). The effectiveness of enrichment activities in giving kindergarten children the concepts of peace. (PhD), Umm Al-Qura University, Saudi Arabia.

Al-Sharqawi, M. (2014). Peace begins from kindergarten. Retrieved from http://www.ahram.org.eg/NewsQ/279923.aspx

Al-Tamimi, A. (2012). The impact of television programs on the formation of awareness among children and young people in the Arab world through the introduction of bad example. Paper of the Conference of Education and Learning Skills and Education. Bahrain.

Brenes, A. (2008). Education for Sustainable Development Based on the Earth Charter. In Factis Pax 2, no.1: pp.1-29, Mische, Patriacia \& Harris, Ian, "Environmental Peacemaking, Peacekeeping and Peace building". In The Encyclopedia of Peace Education, edited by Monish Baja. Charlotte, NC: Information Age Publishing.

Dhaifullah, A. (2008). The effectiveness of a training program for the development of emotional intelligence in academic and social adjustment and in attitudes towards school among gifted students in Jordan. Faculty of Higher Educational Studies. Amman Arab University for Graduate Studies.

DiaaAlmustakball. (2013). Kindergartens in Oman. Retrieved from www.Madarisna.ifo/?p=37767

Education, M. O. (2011). Self-Learning "Omani Curriculum for Kindergarten. Retrieved from www.moe.gov.om/portal/sitebuilder/sites/EPS/Arabic/../kg2.aspx

Education, M. O. (2017). Education System in Oman. Oman: Oman Education Portal.

George, D., \& Mallery, P. (2016). IBM SPSS statistics 23 step by step: A simple guide and reference. Routledge.

Goleman, D. (1998). Working with emotional intelligence. New York: Bantam.

Goleman, D. (2000). Emotional intelligence. New York: Washington Press.

Johnson, D., \& Johnson, R. (2001). Teaching students to be peacemakers: A Meta-Analysis. Paper presented at the Annual Meeting of the American Educational Research Association. Seattle, WA, April 10-14, 2001.

McKinley, L. (2007). Conflict and peacemaking in an early childhood classroom: A grounded theory approach. PhD, Southern Illinois University at Carbondale. 
INTERNATIONAL JOURNAL OF ACADEMIC RESEARCH IN BUSINESS AND SOCIAL SCIENCES

Vol. 10, No. 5, May, 2020, E-ISSN: 2222-6990 @ 2020 HRMARS

Ministry of Social Development. (2014). Omani Child Law. Issued by Royal Decree No. 22/2014. Sultanate of Oman.

Nations, U. (2015). Preventing conflict, transforming justice and ensuring peace. A global study on the implementation of United Nations Security Council Resolution 1325. United State.

Othman, F., \& Rizk, M. (2002). Emotional intelligence scale: Understandable and measured. Cairo: Arab Thought House. Egypt.

Reardon, B. (2009). Human Rights Learning: Pedagogies and Politics of Peace. (Master), University of Puerto Rico.

Shore, R. (1991). What have we learned? In Rethinking the brain. New York: Families \& Work Institute. Sommerfelt, O., \& Vambheim, V. (2008). "The Dream of the Good", A peace at an Individual Level. Journal of peace Education, v5 n1 79-95 March 2008.

Sulaimani, A. (2015). A training program based on the skills of emotional intelligence in the development of motivation for achievement in the teachers of intermediate education. A field study. Department of Social Sciences, Mohammed Khaydar University. Algeria.

Supreme Planning Council. (2019). Oman Vision 20/40. Muscat. Oman.

Tillman, D., \& Colomina, P. (2001). LiVEP (Educator Training Guide). Living Values: An Educational Program. Health Communications, Inc. Deerfield Beach, Florida.

Wave. (2013). Curriculum. Retrieved from www.thewaveprivateschool.edu.om/ar/content/?p=kgcurriculm.

Zidane, A., \& Imam, K. (2002). Emotional intelligence and its relationship to learning methods and some of dimensions. Journal of Arabic Studies in psychology, 2(1). 